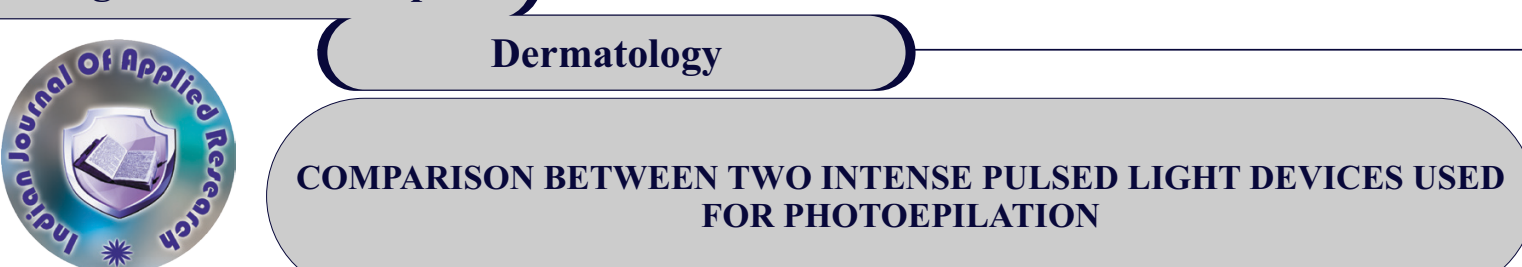

\section{Honório Sampaio} Menezes

\section{Roberto Chacur}

Simone Merceo

Bacchi Cirino

Miguel D'Avilla

Sobrinho

Nívea Maria Bordin da Silva Chacur
$\mathrm{MD}, \mathrm{PhD}$ in medicine, Leger Clinic, Porto Alegre, Brazil

MD, Surgeon, Leger Clinic, Porto Alegre, Brazil

Physio, Leger Clinic, Porto Alegre, Brazil

MD, Leger Clinic, Porto Alegre, Brazil

ABSTRACT Background: Unwanted hair growth is a common aesthetic problem. Intense pulsed light hair removal has emerged as a leading treatment option for long-term depilation.

Material and methods: Patients with phototypes I to III $(n=800)$ were subjected to 4 regular sessions $(n=3200)$ of intense pulsed light, with 2 months follow-up at the end of treatment. Two devices (Silk'n, and Rejuvene) were analyzed about adverse effects and satisfaction.

Observation and results: This study of $3.200 \mathrm{ILP}$ sessions did not show any serious side effects and the number of side effects was minimal ( $8.75 \%$ to $10.5 \%)$. Patient satisfaction was over $90 \%$. Both devices provided a similar and significant reduction in hair density.

Conclusions: Both tested sources proved its safety and efficacy for hair removal. Patient satisfaction scores were in agreement with the treatment efficacy. The incidence of side effects has no difference between devices. Axillary bromhidrosis was an unexpected side effect.

KEYWORDS : Bromhidrosis, Skin, Lasers, Hair, Intense Pulsed Light Therapy.

\section{INTRODUCTION}

Historically, the use of Intense Pulsed Light (IPL) is quite recent. The use of polychromatic infrared light was first described in 1976 by Muhlbauer et al. 1 to treat vascular malformations. The photothermolysis of pigmented structures such as cells or organelle using selective absorption was described in detail in 19832, in 1990 Goldman and Eckhouse3 described a high intensity flash lamp as a novel way to treat vascular injuries that was called intense pulsed light and was commercially launched as medical device only in 1994.

Nowadays the most used cosmetic procedure is depilation by IPLs with excellent results when performed by a trained professional. The fact must be stressed that the success of this treatment largely depends on careful patient selection, of adequate assessment of the cases, and pre and postoperative care. Also, maintenance treatment with additional sessions may be necessary and, as with any cosmetic procedure, good counseling has an important role on the therapeutic outcome ${ }^{4}$.

However, the huge amount of selectable treatments with different configurations increases the risk of side effects due to unspecific thermal damage. Other situations, such as the use of gel, cooled pointer, weight of the pointer, light spectrum variations and irregularities according to applied pulse, especially ILPs with small capacitor, are other obstacles to a good outcomes

Thus, this study aims at studying the depilation effect of 2 IPL devices and to relate it to the degree of patient satisfaction after undergoing this therapy and to verify possible complications of both devices.

\section{MATERIALS AND METHODS}

This study is a prospective cohort of the patients' degree of satisfaction about efficiency and possible complications resulting from the use of IPL in depilation comparing 2 devices was performed.

Patients seeking axillae depilation at the private clinic were selected. Every other patient was treated with the same IPL (intercalation of portable and fixed ones) as both have proven efficacy and are licensed. Inclusion criteria were ages between 18 and 50 years, female gender, Fitzpatrick I to III.

The portable device used was the Silk'n (Silk'n, Home Skinovations, Kfar Saba, Israel ; lem= $475-1.200 \mathrm{~nm}$, fluency of 3-5 J/cm2, pulse duration $<1$ millimillisecond, exposure size $20 \mathrm{~mm} 30 \mathrm{~mm}$ ) without head cooling and gel (ANVISA 80279420022).

The bench device (fixed) was the Rejuvene, with fluency between 18 and $24 \mathrm{~J} / \mathrm{cm} 2$, filter size $650 \mathrm{~nm}$, with gel and head cooling (ANVISA 80279420025).

Sufficient pulses of light to fill the hairy area of the axillae, generally 8 pulses, were triggered without passing the device once more. Immediately after each session, the patients were asked about pain or discomfort during the procedure and any adverse effects were observed. The sessions were repeated at 30-day intervals until a total of 4 sessions. Thereafter, the degree of satisfaction with the treatment was assessed using one of the possible answers: not satisfied; a little satisfied; satisfied; very satisfied (satisfaction questionnaire Likerttype scale). Also, observed adverse effects of the IPL (redness, white spots, dark spots, blisters, bad odor, increase of hairs, not effective and others), Perception of hair reduction (from $10 \%$ to $>90 \%$ ) were recorded. Collected data were filed to preserve the patient's identity, but without affecting any treatment needed.

Statistical analysis was performed using the SPSS 22 system; analysis of data was done applying the chi-square test and Pearson's correlation test (significance level $=0.05$ ).

The design study was approved by the Research Ethics Committee IC/FUC (CAAE protocol number 31539014.1.0000.5333), and all subjects signed the Informed Consent Form.

\section{RESULTS}

Eight hundred patients were included in the cohort study and their management was analyzed in detail, divided in 2 groups of 400 , treated with 3.200 IPL sessions to remove hair from the axillae.

Table 1 shows the satisfaction rate, on both devices, over $90 \%$ of the patients were satisfied with the treatment performed $(p<0.01)$.

Table 1. Details of the subjective assessment of satisfaction with the treatment.

\begin{tabular}{|l|c|c|c|c|c|}
\hline & $\begin{array}{c}\text { Not } \\
\text { Satisfied }\end{array}$ & $\begin{array}{c}\text { Slightly } \\
\text { Satisfied }\end{array}$ & Satisfied & $\begin{array}{c}\text { Very } \\
\text { Satisfied }\end{array}$ & $\begin{array}{c}\text { Extremely } \\
\text { Satisfied }\end{array}$ \\
\hline $\mathrm{AP}(\mathrm{n}=400)$ & $4(1.00)$ & $16(4.00)$ & $115(29.00)$ & $174(43.50)$ & $91(22.75)$ \\
\hline $\mathrm{AF}(\mathrm{n}=400)$ & $6(1.50)$ & $21(5.25)$ & $120(3.25)$ & $159(39.75)$ & $94(23.50)$ \\
\hline
\end{tabular}

$\mathrm{AP}=$ portable device; $\mathrm{AF}=$ fixed device. $(\%)$ 
About $90 \%$ of the patients did not mention any problem during the treatment of IPL at the axillae (Table 2). Hypopigmentation, blisters, leukotrichia, ecchymosis, flaking, scars, edema and itching were not mentioned. A rare effect bromhidrosis occurred in both group, no statistic difference was found $(\mathrm{p}=0.22)$, similar occurred on hyper pigmentation, hypertrichosis end erythema.

Table 2. Observed adverse effects.

\begin{tabular}{|c|c|c|c|c|c|c|c|}
\hline & $\begin{array}{c}\text { No } \\
\text { problem }\end{array}$ & $\begin{array}{c}\text { Erythe } \\
\text { ma }\end{array}$ & $\begin{array}{c}\text { Hyper } \\
\text { Pigmen } \\
\text { tation } \\
\mathrm{P}=0.16\end{array}$ & $\begin{array}{c}\text { Bromhid } \\
\text { rosis } \mathrm{P}= \\
0.22\end{array}$ & $\begin{array}{c}\text { Hypertri } \\
\text { chosis } \\
\mathrm{P}=0.40\end{array}$ & $\begin{array}{c}\text { No } \\
\text { effect }\end{array}$ & Burning \\
\hline $\begin{array}{c}\mathrm{AP}(\mathrm{n} \\
=400)\end{array}$ & $\begin{array}{c}362(90 . \\
50)\end{array}$ & $\begin{array}{c}3 \\
(0.75)\end{array}$ & $8(2.00)$ & $9(2.25)$ & $\begin{array}{c}10 \\
(2.75)\end{array}$ & $\begin{array}{c}4 \\
(1.00)\end{array}$ & $4(1.00)$ \\
\hline $\begin{array}{c}\mathrm{AF}(\mathrm{n} \\
=400)\end{array}$ & $\begin{array}{c}354(88 \\
50)\end{array}$ & $\begin{array}{c}4 \\
(1.00)\end{array}$ & $\begin{array}{c}13 \\
(3.25)\end{array}$ & $6(1.50)$ & $\begin{array}{c}13 \\
(3.25)\end{array}$ & $4(1.00)$ & $6(1.50)$ \\
\hline
\end{tabular}

$\mathrm{AP}=$ portable device; $\mathrm{AF}=$ fixed device. $(\%)$

\section{Table 3 .Patients' perception on the degree of treatment} effectiveness.

\begin{tabular}{|c|c|c|c|c|c|c|c|c|}
\hline & $\geq 10 \%$ & $20 \%$ & $40 \%$ & $50 \%$ & $60 \%$ & $80 \%$ & $\geq 90 \%$ & $\begin{array}{c}\text { Not } \\
\text { obser } \\
\text { ved }\end{array}$ \\
\hline $\begin{array}{c}\mathrm{AP}(\mathrm{n}=4 \\
00)\end{array}$ & $\begin{array}{c}12 \\
(3.00)\end{array}$ & $\begin{array}{l}(4.50) \\
(10.75)\end{array}$ & $\begin{array}{c}(10.00) \\
(15.00)\end{array}$ & $.00)$ & $\begin{array}{c}(16.75) \\
(5.25)\end{array}$ \\
\hline $\begin{array}{c}\mathrm{AF}(\mathrm{n}=4 \\
00)\end{array}$ & $\begin{array}{c}11 \\
(2.75)\end{array}$ & $\begin{array}{c}19 \\
(4.75)\end{array}$ & $\begin{array}{c}41 \\
(10.25)\end{array}$ & $\begin{array}{c}46 \\
(11.50)\end{array}$ & $\begin{array}{c}67 \\
(16.75)\end{array}$ & $\begin{array}{c}115 \\
(28.75)\end{array}$ & $\begin{array}{c}78 \\
(19.50)\end{array}$ & $\begin{array}{c}23 \\
(6.00)\end{array}$ \\
\hline
\end{tabular}

$\mathrm{AP}=$ portable device; $\mathrm{AF}=$ fixed device $(\%)$

According to the patients' perception (Table 3) both devices were effective reducing hair over $82 \%$.

\section{DISCUSSION}

Photothermolysis of pigmented structures, cells, and organelles by selective absorption of pulsed irradiation was described in detail in 19832. In 1990, Goldman and Eckhouse described a light with higher intensity coming from a flash lamp as an adequate tool to treat vascular lesions. With the improvement of the IPL devices, the first medical device was launched in 19943.

The combination of specific wavelengths, pulse time, pulse intervals, and fluency enables the treatment of several skin types or disorders such as acne vulgaris, pigmented lesions, vascular lesions, unwanted hair growth, photoageing, scars6, angiokeratoma 7 and epilation ${ }^{8}$.

Depilation with laser (alexandrite, diode, neodymium, YAG and Ruby laser) and intense pulsed light are frequently used. Pain, skin redness, swelling, burned hair and pigment changes are reported as adverse effects9.

The skin type has to be documented according to the Fitzpatrick10 scale to adjust photophysical parameters; in our study only patients with phototype 1 to 3 were enrolled.

We used a 4-week interval between depilation sessions because the normal growth period of underarm hair is 25 days and its cycle lasts 18 months or 540 days $^{11}$

Common side effects that occur one or more days after IPL are swelling and erythema. The latter occurred in $0.75 \%$ of patients treated with portable devices and $1.0 \%$ of patients treated with fixed devices. Blisters and scaling are signs of excessive fluency; we had none of these side effects in our study.

Long-lasting or irreversible adverse effects are alterations of the pigment as hypopigmentation or hyperpigmentation. They can be avoided adjusting wavelengths and fluencies to the skin type and the treated area12. In our series hyperpigmentation occurred in $2.0 \%$ of the cases treated with portable device and $3.25 \%$ with fixed device. Hyperpigmentation with portable IPL may have happened due to the type of exposure, as the lamp is in direct contact with the skin without a cooling or diffusing gel, even when fluency is not $>a 5 J / \mathrm{cm}^{2}$.

In the study by Souza et al.13 adverse effects included pain, inflammation and crusts, the latter only observed when IPL was used. It is possible that in that study crusts occurred due to the use of $36 \mathrm{~J} / \mathrm{cm} 2$ and not in our study because we used lower fluency $(24 \mathrm{~J} / \mathrm{cm} 2)$ without paradoxical excessive hair growth due to the same reason. In the same study, Souza et al. did not report significant difference in the subjective assessment of the final result with different techniques, achieving similar results to our findings. They also concluded that there was less pain and lower incidence of side effects when diode laser was used, rather than IPL, which probably is due to the high fluency of IPLs, which are unnecessary to obtain good results.

Cameron et al.14 compared diode laser (Lightsheer) with IPL device (Luminette) 6 weeks after treatments. Both substantially reduced hair count in spite of higher pain scores and inflammation. Neither significant pain nor inflammation was documented in our study.

McGill et al.15 did a split-face randomized trial of facial depilation using alexandrite laser (GentleLaser) and a IPL (GentleLaser), and satisfaction was higher with the use of laser, despite significantly more side effects. Satisfaction rates in our study were similar $(95.25 \%$ AP and $93.50 \% \mathrm{AF}$ ) without significant difference.

Amin and Goldberg 16 assessed the efficacy of an IPL device (red filter), a yellow filter IPL, a $810 \mathrm{~nm}$ diode laser and a $755 \mathrm{~nm}$ alexandrite laser in patients $(n=10)$ with undesired hair at the back of the thigh. Hair count at 1, 3 and 6 months after the second session showed important hair reduction (50\%) for all devices (not significant). Normal hair count at the axillae is about 350 hairs; in our study subjective impression of less hair was recorded on a scale completed by the patient. As the efficacy of the used devices has already been proven, we thought hair count to be unnecessary.

Gan and Graber17 did a review and concluded that there was enough evidence to state that laser and IPL produced long-term removal of undesired hair. Klein et al.18 conducted a randomized, controlled trial with one year follow-up after the last session comparing laser and IPL applied to the axillae and concluded that both methods are highly effective and safe with long-term results; diode laser is more painful, but with quicker onset of results.

Bjerring and Christiansen 19 compared the efficacy of an IPL device (Elipse) with a normal mode ruby laser (Epitouch) for hair removal in a split-face study and reported a mean hair count reduction of $49.3 \%$ (IPL) versus $21.3 \%$ (ruby laser) and concluded that IPL was 3.94 times more efficacious than ruby laser. This study shows the efficacy of IPL treatment to remove hair in only 3 sessions; in our study we used 4 sessions and obtained an efficacy above $50 \%$ in $82 \%$ of the treated patients.

Radmanesh et al.20 studied the side effects of IPL (Lumina) in hair removal of 1.000 women treated every 4-6 weeks with a total of $\geq 8$ sessions and a follow-up until 20 months. Using $30 \mathrm{~J} / \mathrm{cm} 2$ and fluency of 15 the authors reported burns as a frequent adverse effect, as well as post-inflammatory hyperpigmentation $(\mathrm{n}=75)$, blisters and erosion $(n=64)$, leukotrichia, $(n=40)$ folliculitis $(n=35)$, post-inflammatory hypopigmentation $(\mathrm{n}=10)$ and scar tissue $(\mathrm{n}=1)$. Unexpectedly, paradoxical hypertrichosis occurred in 12 cases. The same author conducted another study 21 and also found paradoxical increase of hair density and thickness after photodepilation (5.1\%) with IPL (Lumenis) in 991 women treated with 695,755 , and $645 \mathrm{~nm}$ filter cutoff and observed for 23 months. The assessment of side effects in our population (800 patients submitted to 3.200 IPL sessions) also showed the presence of paradoxical hypertrichosis $(2.75 \% \mathrm{AP}$ and $3.25 \% \mathrm{AF})$, hyperpigmentation $(2.00 \% \mathrm{AP}$ and $3.25 \% \mathrm{AF})$, and erythema $(0.75 \%$ $\mathrm{AP}$ and $1.00 \% \mathrm{AF}$. We had important increase of axillary odor (bromhidrosis) in 3.75\%, an IPL adverse effect not yet documented in literature22. No other adverse effects were observed, probably because we used $24 \mathrm{~J} / \mathrm{cm} 2$ and $3-5 \mathrm{~J} / \mathrm{cm} 2$ in our IPL devices.

Alster and Tanzi23 assessed the safety and efficacy of a portable IPL used at home to remove hair $(n=20$; skin phototype 1-4); the hair to be removed was dark at the terminal part and on non-facial sites (axillae, forearms, groin, and legs). Three treatments in 2-week intervals were self-administered using a portable computer (Silk'n, Home Skinovations, Kfar Saba, Israel). The authors alleged that safety mechanisms would protect the eyes and IPL head cooling was not necessary, facts confirmed in a study by Eadie et al.24. The authors reported that hair count was reduced in 37.8 to $53.6 \%$ at the sixth postreatment month. Besides erythema (25\%) no other side effect or 
complication were observed. Patient satisfaction was high. We used the same parameters and subjective assessment for same IPL device (Silk'n) in 400 patients that received 1.600 sessions of underarm depilation and noticed the presence of erythema $(0.75 \%)$, paradoxical hypertrichosis $(2.75 \%)$, bromhidrosis $(2.25 \%)$, burning sensation $(1.00 \%)$, and hyperpigmentation $(2.00 \%)$. The degree of satisfaction also was high $(92.25 \%)$ and the device was efficient $(82 \%)$. The biggest problem was the almost unaffordable cost of the lamp. Its mean price in Brazil was U\$2 05.00 per lamp that allows 700 shots, generally 16 shots in every underarm depilation session.

The final assessment of hair reduction was only done 4 weeks after the last session, and the long-term result was not verified. This can be considered a limitation of the present study that also did not count hairs. As one of the aims was to observe possible side effects of IPLs, one of them a domestic device, this seemed irrelevant because the efficacy IPL in depilation has already been proven. It has to be stressed that similar technologies can have different modes of operation in practice.

The presence of difficult to treat bromhidrosis after IPL was an unexpected side effect that is not mentioned in literature.

\section{CONFLICT OF INTEREST}

No potential conflict of interest relevant to this article was reported.

\section{REFERENCES}

Muhlbauer W, Nath G, Kreitmair A. Treatment of capillary hemangiomas and nevi flammei with light. Langenbecks Arch Chir 1976;(suppl):91-94.

2 Anderson RR, Parrish JA. Selective photothermolysis: Precise microsurgery by Anderson RR, Parrish JA. Selective photothermolysis: Precise microsing
selective absorption of pulsed radiation. Science 1983;220(4596):524-527.

3 Goldman MP. Treatment of benign vascular lesions with the photoderm VL highintensity pulsed light source. Adv Dermatol 1997;13:503-521.

4 Buddhadev RM. Standard guidelines of care: Laser and LIP hair reduction. Indian J Dermatol Venereol Leprol. 2008;74(7):68-74.

5 Eadie E, Miller P, Goodman T, Moseley H. Time-resolved measurement shows a spectral distribution shift in an intense pulsed light system. Lasers Med Sci 2009;24(1):35-43.

6 Erol OO, Gurlek A, Agaoglu G, Topcuoglu E, Oz H. Treatment of hypertrophic scars and keloids using intense pulsed light (LIP). Aesthetic Plast Surg 2008;32(6):902-909.
kel

7 Morais P, Santos AL, Baudrier T, Mota AV, Oliveira JP, Azevedo F. Angiokeratomas of Fabry successfully treated with intense pulsed light. J Cosmet Laser Ther 2008;10(4): 218-222.

8 Babilas P., Schreml S., Szeimies R. M., Landthaler M. Intense Pulsed Light (LIP): A Review. Lasers Surg. Med. 42:93-104, 2010

9 Merete H, Gøtzsche P. C. Laser and photoepilation for unwanted hair growth. Cochrane Database Syst Rev. 2006 Oct 18;(4):CD004684. Review.

10 Fitzpatrick TB. The validity and practicality of sun-reactive skin types I through VI. Arch Dermatol 1988;124(6):869-871.

11 Gaucher Catherine. Relation entre cycle pilaire et epilation laser: etude ouverte sur 492 cas.Dermatologue, 2001.Consultado em 21 de abr de 2014.

12 Adamic M, Troilius A, Adatto M, Drosner M, Dahmane R. Vascular lasers and LIPS: Guidelines for care from the European Society for Laser Dermatology (ESLD). J Cosmet Laser Ther 2007;9(2):113-124

13 Souza FHM , Ribeiro CF, Weigert S, Schmidt JV, Fabricio LZ, Ataide DST. Estudo comparativo de uso de Laser de diodo (810nm) versus luz intensa pulsada (filtro $695 \mathrm{~nm}$ ) em epilação axilar. Surgical \& Cosmetic Dermatology 2(3):185-90, 2009

14 Cameron H, Ibbotson SH, Dawe RS, Ferguson J, Moseley H. Within-patient right-left blinded comparison of diode $(810 \mathrm{~nm})$ laser therapy and intense pulsed light therapy for blinded comparison of diode $(810 \mathrm{~nm})$ laser therapy

15 McGill DJ, Hutchison C, McKenzie E, McSherry E, Mackay IR. A randomised, splitface comparison of facial hair removal with the alexandrite laser and intense pulsed light system. Lasers Surg Med 2007;39(10):767-772.

16 Amin SP, Goldberg DJ. Clinical comparison of four hair removal lasers and light sources. J Cosmet Laser Ther 2006;8(2):65-68.

17 Gan SD, Graber EM.Laser hair removal: a review. Dermatol Surg. 2013 Jun;39(6):82338.

18 Klein A, Steinert S, Baeumler W, Landthaler M, Babilas P. Photoepilation with a diode laser vs. intense pulsed light: a randomized, intrapatient left-to-right trial. Br J Dermatol. 2013 Jun;168(6):1287-93.

19 Bjerring P, Christiansen K. Intense pulsed light source for treatment of small Bjerring P, Christiansen K. Intense pulsed light source for treatment
melanocytic nevi and solar lentigines. J Cutan Laser Ther 2000;2(4):177-181.

20 Radmanesh M, Azar-Beig M, Abtahian A, Naderi AH. Burning, paradoxical hypertrichosis, leukotrichia and folliculitis are four major complications of intense pulsed light hair removal therapy. J Dermatolog Treat 2008;19(6):360-363.

21 Radmanesh M. Paradoxical hypertrichosis and terminal hair change after intense pulsed light hair removal therapy. J Dermatolog Treat 2009;20(1):52-54.

22 Mao GY, Yang SL, Zheng JH. Etiology and management of axillary bromidrosis: a brief review. Int J Dermatol. 2008 Oct; 47(10):1063-8.

23 Alster TS, Tanzi EL. Effect of a novel low-energy pulsed-light device for home-use hair Alster TS, Tanzi EL. Effect of a novel low-ene

24 Eadie E, Miller P, Goodman T, Moseley H. Assessment of the optical radiation hazard from a home-use intense pulsed light (LIP) source.Lasers Surg Med. 2009 Sep;41(7):534-9 